would cost $€ 25$ million (US\$35 million), and is unlikely to be funded, says Frank Wilhelms of the Alfred Wegener Institute for Polar and Marine Research in Bremerhaven, Germany, which houses one of four major ice-core facilities in Europe. The International Partnerships in Ice Core Sciences (IPICS), an organization of scientists, drillers and engineers from 18 nations, has also said that urgent action is needed to prevent ice cores degrading.

In the interim, Jeffrey Severinghaus, an IPICS steering-committee member from the Scripps Institute of Oceanography in La Jolla, California, says some institutions like his are building smaller units to keep parts of cores at $-50^{\circ} \mathrm{C}$. These units can be created for about $\$ 15,000$, but the necessary freezer adaptations void warranties and there are concerns that keeping sections of ice cores in many different locations may hamper researchers' access.

His lab is currently studying oxygen/nitrogen ratios in ice cores drilled last year for the Western Antarctic Ice Sheet Divide Ice Core project, a collaboration of US research groups. Preliminary comparisons with the Byrd ice core, drilled in 1968 in Western Antarctica, show that oxygen has been lost in the older core during storage, he says.

Rex Dalton

were persuaded to share by GISAID's terms of access, similar to those of open-source software, in which all users agree to share their own data and give due credit to the originators.

"Indonesia has been supportive of GISAID from the outset," says Widjaja Lukito, a senior policy adviser at the country's ministry of health. He adds that he is watching "with great concern the problems faced by the GISAID Initiative during this pandemic phase". He says that he strongly hopes that "the parties involved will reach the best solution for the sake of global public health".

One flu scientist, who is a member of GISAID's scientific council, adds that EpiFlu is more than just the database computing infrastructure built by the SIB. Considerable effort has been invested by GSAID and its partners in "building trust" between the scientific community and countries who have sequence data to deposit, and in contributing influenza expertise.

Lawyers for both the SIB and GISAID have in the past weeks made confidential settlement offers to each other, and both say they are keen to reach a peaceful settlement. "The SIB is $100 \%$ committed to the EpiFlu database as part of the GISAID initiative. We are working very hard to find the best possible solution for all concerned," says Ron Appel, head of the SIB.

Declan Butler

\title{
Climate data spat intensifies
}

A leading UK climatologist is being inundated by freedom-of-information-act requests to make raw climate data publicly available, leading to a renewed row over data access.

Since 2002, Steve McIntyre, the editor of Climate Audit, a blog that investigates the statistical methods used in climate science, has repeatedly asked Phil Jones, director of the Climatic Research Unit (CRU) at the University of East Anglia, UK, for access to monthly global surface temperature data held by the institute. But in recent weeks, Jones has been swamped by a sudden surge in demands for data.

Several organizations worldwide collect and report global average temperature data for each month. Of these, a temperature data set held jointly by CRU and the UK Met Office's Hadley Centre in Exeter, known as HadCRU, extends back the farthest, beginning in 1850. Although these data are made available in a processed format that shows the global trend, access to the raw data is restricted to academics.

Between 24 July and 29 July of this year, CRU received 58 freedom-of-informationact requests from McIntyre and people affiliated with Climate Audit, requesting access to the data or information about their use. In the past month, the UK Met Office, which receives a cleaned-up version of the raw data from CRU, has received ten requests of its own.

McIntyre, based in Toronto, Ontario, is best known for questioning the validity of the statistical analyses used to reconstruct the past 1,000 years of climate, but has more recently turned his attention to criticizing the quality of global temperature records. Jones concedes that raw climate data have imperfections - such as duplication of stations - but says that such minor errors would not alter the overall global temperature trend. McIntyre insists that he is not interested in challenging the science of climate change or in nit-picking, but is simply asking that the data be made available. "The only policy I want people to change is their data-access policy," he says.
Jones says he can't fulfil the requests because of confidentiality agreements signed in the 1990s with some nations, including Spain, Germany, Bahrain and Norway, that restrict the data to academic use. In some cases, says Jones, the agreements were made verbally, and in others the written records were mislaid during a move.

He says he is now working to make the data publicly available online. As Nature went to press, Jones was expected to post a statement on the CRU website to that effect, including any existing confidentiality agreements. Jones says any such data release "needs to be done in a systematic way".

"We're trying to make them all available," says Jones. "We're consulting with all the meteorological services - about 150 members [of the World Meteorological Organization] - and will ask them if they are happy to release the data." A spokesperson for the Met Office confirmed this, saying "we are happy for CRU to take the lead on this, as they are their data".

But getting the all-clear from other nations won't be without its challenges, says Jones, who estimates that it could take several months. In addition, some nations may object if they make money by selling their wind, sunshine and precipitation data.

The dispute is likely to continue for some time. McIntyre is especially aggrieved that Peter Webster, a hurricane expert at the Georgia Institute of Technology in Atlanta, was needs to be done in a systematic way." recently provided with data that had been refused to him.

Webster says his team was given the station data for a very specific request that will result in a joint publication with Jones. "Reasonable requests should be fulfilled because making data available advances science," says Webster, "but it has to be an authentic request because otherwise you'd be swamped."

Indeed, Jones says he has become "markedly less responsive to the public over the past few years as a result of this". Olive Heffernan 